\title{
Evaluasi Overall Equipment Effectiveness Sebagai Upaya Perbaikan Produktivitas Mesin Produksi Kain Non-Wovens (Studi Kasus PT. Megah Sembada Industries)
}

\author{
Evaluation of Overall Equipment Effectiveness As An Effort To \\ Improve The Productivity Of Non-Wovens Fabric Production \\ Machines \\ (Case Study of PT. Megah Sembada Industries)
}

\author{
Hartono $^{1}$, Aldi Pramana Putra ${ }^{2}$, TinaHernawati Suryatman ${ }^{3}$ \\ 1,2. Program Studi Teknik Industri, Fakultas Teknik, Universitas Muhammadiyah Tangerang \\ 1hartono@umt.ac.id, 2ªldypramana4@gmail.com, tinahernawati76@gmail.com
}

\begin{abstract}
The manufacturing industry has a system for applying machinery, labor, equipment and raw materials to be transformed into a product that has a sale value. Production machinery and equipment are the main resources that cannot be separated from the overall resource system owned by the company. At PT. Sumber Wovens Utama production machines are used nonstop and cause a decrease in performance of these machines which include frequent breakdowns, loss of ideal speed, and poor quality. The purpose of this study is to determine the overall value of the effectiveness of the production machinery at this time, to find the root cause of the overall equipment effectiveness value is not as expected, and to provide an improvement to the cause of the low value of the overall equipment effectiveness of the non-wovens fabric production machine. The method used in this research is the Overall Equipment Effectiveness Method to calculate the level of effectiveness and productivity of production machines, Fishbone Diagrams to solve problems in projects and Analysis of 5 why to provide improvements to the level of productivity of these machines. The results showed that the average overall equipment effectiveness value for the period November 2018 - April 2019 was $83.2 \%$, this value was still below the world class standard of $85 \%$. Therefore, it is given an improvement over the overall equipment effectiveness value not being achieved by making regular maintenance schedules for production machines, making standard product changeover procedures, making standard parameters for each type of product and updating it every 1 month, etc. so that it gets good results, namely increases the overall equipment effectiveness value of the production machine to be $88.30 \%$.

Keywords: Overall Equipment Effectiveness, Fishbone Diagram, 5 why analys, Mesin Produksi, Kain Non-wovens, Production Machine, Non-wovens Fabric
\end{abstract}

\begin{abstract}
ABSTRAK
Dunia industri manufaktur memiliki sebuah sistem untuk mengaplikasikan mesin, tenaga kerja, peralatan dan bahan baku untuk di transformasikan menjadi sebuah produk yang mempunyai nilai jual. Mesin dan peralatan produksi merupakan sumber daya utama yang tidak terlepas dari sistem sumberdaya secara keseluruhan yang dimiiki oleh perusahaan. Pada PT. Megah Sembada Industri mesin-mesin produksi digunakan nonstop dan menyebabkan penurunan kinerja terhadap mesin tersebut yang diantaranya mesin sering breakdown, kehilangan kecepatan ideal, dan kualitas yang buruk. Tujuan penelitian ini adalah untuk mengetahui nilai overall equipment effectiveness mesin produkssi saat ini, mencari akar penyebab nilai overall equipment effectiveness tidak sesuai harapan, dan memberi perbaikan terhadap penyebab rendahnya nilai overall equipment effectiveness mesin produksi kain non-wovens. Metode yang digunakan dalam penelitian ini yaitu Metode overall equipment effectiveness untuk untuk menghitung tingkat efektifitas dan produktifitas mesin produksi, Diagram Fishbone untuk memecahkan masalah pada proyek dan Analisa 5 why untuk memberikan perbaikan tingkat produktifitas mesin tersebut. Hasil Penelitian menunjukan bahwa rata-rata nilai overall equipment effectiveness periode November 2018 - April 2019 sebesar 83,2\% nilai ini masih dibawah standar world class yaitu $85 \%$. Oleh karena itu diberikan perbaikan atas ketidak tercapaian nilai overall equipment effectiveness tersebut dengan membuat jadwal perawatan berkala terhadap mesin produksi, membuat standar prosedur changeover produk, membuat
\end{abstract}


parameter standar tiap jenis produk dan memperbaruinya kurun waktu 1 bulan sekali, dsb sehingga mendapatkan hasil yang baik yaitu kenaikan nilai overall equipment effectiveness mesin produksi menjadi $88,30 \%$.

Kata Kunci: Overall Equipment Effectiveness, Fishbone Diagram, 5 why analys, Mesin Produksi, Kain Non-wovens

\section{PENDAHULUAN}

\subsection{Latar Belakang}

Peralatan merupakan sumber daya utama yang tidak terlepas dari sistem sumberdaya secara keseluruhan yang dimiliki oleh perusahaan. Kemampuan perusahan dalam penerapan suatu teknologi harus ditunjang oleh kemampuan menjaga peralatan yang berkaitan dengan teknologi ini. Peralatan juga berkaitan dengan efektifitas mesin sehingga dalam jangka panjang akan berhubungan dengan pencapaian tujuan perusahaan.

PT. Sumber Wovens Utama adalah salah satu perusahaan yang bergerak di manufaktur textile, produk yang mereka hasilkan berupa kain non-wovens dengan bahan baku utama adalah kapas sintetis. mesin-mesin produksi yang mereka gunakan umumnya bekerja 24 jam nonstop selama 6 hari kerja. Akibat penggunaan mesin yang terus menerus tersebut membuat penurunan kinerja terhadap mesin menjadi semakin cepat mengakibatkan mesin sering breakdown, kehilangan actual speed, kualitas yang buruk yang mengakibatkan cacat produk, down time mesin menjadi tidak teratur dan berdampak terhadap penurunan produktivitas yang dihasilkan. Selain itu, perawatan terhadap mesin produksi yang tidak maksimal memperburuk penurunan kinerja terhadap mesin-mesin produksi tersebut. Pada gambar 1 dibawah ini adalah

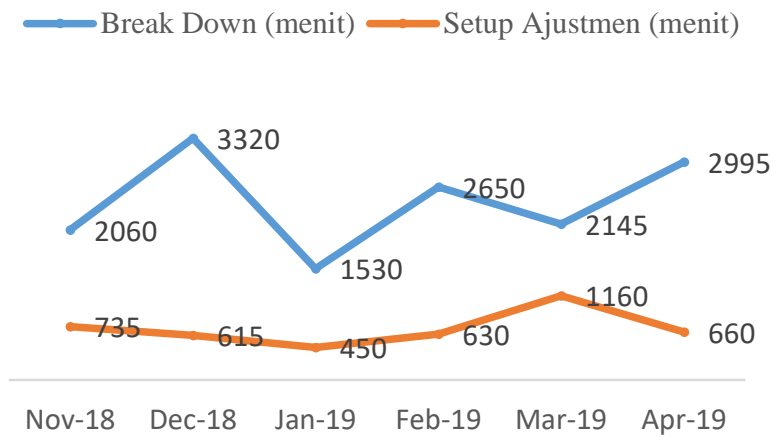

Gambar 1 Diagram Breakdown dan Setup Adjustement

Dari gambar 1 diatas dapat dilihat bahwa masih terjadi waktu breakdown dan setup adjustement mesin produksi yang masih tinggi. Selain itu, pada gambar 1.3 dibawah menerangkan lose time akibat adanya minor stoppage dan speed lose.

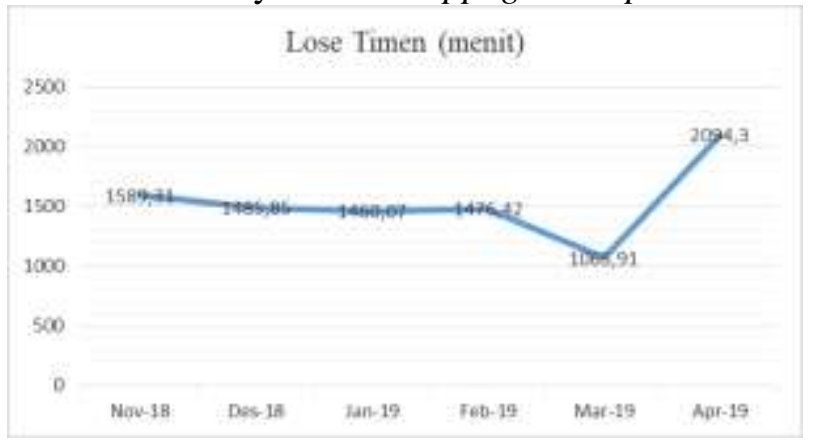

Gambar 2 Diagram Breakdown dan Setup Adjustement

Perlu adanya tindakan untuk mengantisipasi atau bahkan meminimalisir terjadinya penurunan produktivitas mesin yang disebabkan oleh kendala-kendala diatas, Oleh karena 
itu, dalam penelitian ini akan dilakukan penelitian mengenai "Evaluasi Overall Equipment Effectiveness Sebagai Upaya Perbaikan Produktivitas mesin Produksi Kain Non-wovens".

\subsection{Tinjauan Pustaka}

\section{Overall Equipment Effectiveness}

Overall Equipment Effectiveness (OEE) merupakan efektivitas peralatan secara keseluruhan untuk mengevaluasi seberapa performance peralatan. OEE juga digunakan untuk memperbaiki produktivitas sebuah perusahaan sebagai langkah pengambilan keputusan. Overall Equipment Effectiveness (OEE) merupakan metode yang digunakan sebagai alat ukur dalam penerapan program Total Productive Maintenance (TPM) guna menjaga peralatan agar pada kondisi ideal dengan menghapuskan six big losses. Analisis OEE digunakan sebagai parameter untuk mengetahui tingkat kehandalan mesin dengan parameter sebegai berkut :

a. Availability Rate

Availability rate sebagai ukuran untuk mengukur tingkat efektivitas maintenance peralatan produksi dalam kondisi produksi sedang berlangsung. Menghitung penggunaan waktu kerja dari penggunaan waktu yang tersedia untuk kegiatan operasi mesin atau peralatan. Waktu diukur dari pengurangan waktu kerja (loading time) dengan waktu kerusakan mesin atau peralatan (downtime) dibagi dengan waktu bekerja. Rumus untuk melakukan perhitungan Availability Rate yaitu :

Loading Time $=$ Total menit - Planned Downtime

Operating Time $=$ Loading Time - Downtime $\ldots$

Actual Operating Time $=$ Procesed Amount $\mathrm{x}$ Actual Cycle Tim......

Avaibility time $=\frac{\text { Loading time-Downtime }}{\text { Loading time }} \times 100 \%$

\section{b. Performance Rate / Performance Efficiency}

Digunakan untuk mengukur seberapa efektif peralatan produksi yang digunakan. Perhitungan ini didapatkan dari nilai perkalian keluaran atau output dengan waktu siklus ideal kemudian dibagi dengan waktu operasi. Nilai ini menunjukan kinerja dari sumber daya yang digunakan dalam hal ini adalah mesin produksi. Rumus yang digunakan untuk melakukan perhitungan Performance Ratel Performance Efficiency yaitu :

$$
\text { Performance rate }=\frac{\text { Procesed amount } \mathrm{x} \text { ideal cycle time }}{\text { operation time }} \times 100 \%
$$

c. Quality Rate/ Rate of Quality Products

Untuk mengukur efektivitas proses manufaktur untuk mengeliminasi scrap, rework, dan yield loss. Rumus yang digunakan untuk menghitung Rate of Quality Products yaitu :

$$
\text { Quality rate }=\frac{\text { processed amount-defect amount }}{\text { processed amount }}
$$

\section{d. Overall Equipment Effectiveness}

Yaitu merupakan metode yang digunakan sebagai alat ukur (metrik) dalam penerapan metode Total Productive Maintenance. Overall Equipment Effectiveness berguna untuk menjaga mesin atau peralatan tetap dalam kondisi ideal. Nilai yang dihasilkan dari perkalian tiga rasio kemudian dibandingkan dengan nilai OEE standar dunia. Berikut merupakan perhitungan untuk menghitung nilai OEE.

$\mathrm{OEE}=$ Avaibility $\times$ Performance $\times$ Quality

Menurut (Nakajima, 1988) nilai ideal untuk OEE dan menjadi nilai standard world class yaitu sebesar $85 \%$, dengan nilai Availability Rate ideal diatas 90\%, nilai Performance Efficiency diatas 95\%, dan nilai Rate of Quality Product diatas $99 \%$. 
Tujuan dari perhitungan six big losses adalah untuk mengetahui nilai effektivitas keseluruhan (OEE). Dari nilai OEE ini dapat diambil langkah-langkah untuk memperbaiki atau mempertahankan nilai tersebut. Keenam kerugian tersebut digolongkan menjadi tiga macam yaitu (Nakajima, 1988) :

a. Downtime Losses, terdiri dari :

- Breakdown Losses/ Equipment Failures yaitu kerusakan mesin/ peralatan yang tiba-tiba atau kerusakan yang tidak diinginkan tentu saja akan menyebabkan kerugian, karena kerusakan mesin akan menyebabkan mesin tidak beroperasi menghasilkan output. Hal ini akan mengakibatkan waktu yang terbuang sia-sia dan kerugian material serta produk cacat yang dihasilkan semakin banyak.

- Setup and Adjusment Losses kerugian karena pemasangan dan penyetelan adalah semua waktu setup termasuk waktu penyesuain (adjustment) dan juga waktu yang dibutuhkan untuk kegiatan- kegiatan pengganti satu jenis produk ke jenis produk berikutnya untuk proses produksi selanjutnya.

b. Speed Loss, terdiri dari:

- Idling and Minor Stoppage Losses disebabkan oleh kejadian-kejadian seperti pemberhentian mesin sejenak, kemacetan mesin, dan idle time dari mesin. Kenyataannya, kerugian ini tidak dapat dideteksi secara langsung tanpa adanya alat pelacak. Ketika operator tidak dapat memperbaiki pemberhentian yang bersifat minor stoppage dalam waktu yang telah ditentukan, dapat dianggap sebagai suatu breakdown.

- Reduced Speed Losses yaitu kerugian karena mesin tidak dapat bekerja optimal (penurunan kecepatan operasi) terjadi jika kecepatan aktual operasi mesin/peralatan lebih kecil dari kecepatan optimal atau kecepatan mesin yang dirancang.

c. Defect Loss, terdiri dari :

- Process Defect yaitu kerugian yang disebabkan karena adanya produk cacat maupun karena kerja produk diproses ulang. Produk cacat yang dihasilkan akan mengakibatkan kerugian material, mengurangi jumlah produksi, biaya tambahan untuk pengerjaan ulang termasuk biaya tenaga kerja dan waktu yang dibutuhkan untuk mengolah dan mengerjakan kembali ataupun untuk memperbaiki produk yang cacat. Walaupun waktu yang dibutuhkan untuk memperbaiki produk cacat hanya sedikit, kondisi ini dapat menimbulkan masalah yang

- Reduced Yield Losses disebabkan material yang tidak terpakai atau sampah bahan baku

\section{Pengertian Kain Non-wovens}

Kain Non-Wovens adalah kain yang terbuat dari polypropylene berbentuk serat panjang yang terikat dan tersususn dengan kuat secara kimiawi, mekanik, padas dan perawatan dengan pelarut. Kain jenis ini memiliki kelebihan antara lain, tahan lama, memiliki daya serap air yang cukup tinggi, lembut, elastis. Cukup tahan terhadap api, memiliki daya saring terhadap bakteri. Kain Non-Wovent biasanya digunakan untuk popok bayim produk pembersih wanita, tisu basah, perban, jubbah bedah, filter bensin, filter air, karpet, kemasan, dan kain pelapis.

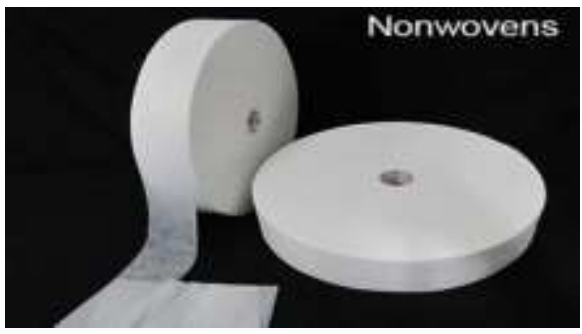

Gambar 3 Kain Non-Wovens 


\section{Fishbone Diagram}

Diagram tulang ikan atau fishbone diagram adalah salah satu metode / tool di dalam meningkatkan kualitas. Sering juga diagram ini disebut dengan diagram SebabAkibat atau cause effect diagram. Diagram sebab akibat ini dikemukakan pertama kali oleh Prof. Dr. Kaoru Ishikawa yang merupakan seorang insinyur Teknik Kimia, sehingga sering juga disebut dengan diagram ishikawa. Metode tersebut awalnya lebih banyak digunakan untuk manajemen kualitas yang menggunakan data verbal (nonnumerical) atau data kualitatif. Dr. Ishikawa juga ditengarai sebagai orang pertama yang memperkenalkan 7 alat atau metode pengendalian kualitas (7 tools). Yakni fishbone diagram, control chart, run chart, histogram, scatter diagram, pareto chart, dan flowchart.

Diagram Fishbone merupakan konsep analisis sebab akibat yang dikembangkan oleh Prof. Dr. Kaoru Ishikawa untuk mendeskripsikan suatu permasalahan dan penyebabnya dalam sebuah kerangka tulang ikan. Dikatakan Diagram Fishbone (Tulang Ikan) karena memang berbentuk mirip dengan tulang ikan yang moncong kepalanya menghadap ke kanan. Diagram ini akan menunjukkan sebuah dampak atau akibat dari sebuah permasalahan, dengan berbagai penyebabnya. Efek atau akibat dituliskan sebagai moncong kepala. Sedangkan tulang ikan diisi oleh sebab-sebab sesuai dengan pendekatan permasalahannya. Dikatakan diagram Cause and Effect (Sebab dan Akibat) karena diagram tersebut menunjukkan hubungan antara sebab dan akibat. Berkaitan dengan pengendalian proses statistikal, diagram sebabakibat dipergunakan untuk untuk menunjukkan faktor-faktor penyebab (sebab) dan karakteristik kualitas (akibat) yang disebabkan oleh faktor-faktor penyebab itu.

Watson (2004) dalam Ilie G. dan Ciocoiu C.N. (2010) mendefinisikan diagram fishbone sebagai alat (tool) yang menggambarkan sebuah cara yang sistematis dalam memandang berbagai dampak atau akibat dan penyebab yang membuat atau berkontribusi dalam berbagai dampak tersebut. Oleh karena fungsinya tersebut, diagram ini biasa disebut dengan diagram sebab-akibat.

Diagram Fishbone (Tulang Ikan)/ Cause and Effect (Sebab dan Akibat)/ Ishikawa telah menciptakan ide cemerlang yang dapat membantu dan memampukan setiap orang atau organisasi/perusahaan dalam menyelesaikan masalah dengan tuntas sampai ke akarnya. Faktor Analisa yang dapat digunakan dalam merancang sebuah Cause Effect Diagram adalah dengan menganalisa dengan menggunakan 4M+1I.

\section{METODOLOGI}

\subsection{Teknik Pengumpulan Data}

\section{Observasi}

Dalam penelitian ini observasi dilakukan untuk mengamati obyek-obyek penelitian seperti observasi terhadap avaibilitas, produktifitas, dan kualitas dari mesin carding kain non-wovens. Observasi ini juga dilakukan untuk mendapatkan data-data primer terhadap penelitian yang sedang dilakukan agar data-data tersebut dapat diolah dan dikembangkan pada proses analisa dan pembahasan penelitian.

\section{Interview}

Untuk menemukan permasalahan-permasalahan terhadap faktor yang paling dominan menyebabkan rendahnya nilai OEE, teknik penupulan data dengan cara interview dapat digunakan, teknik interview ini juga bisa mencari dan mengetahui halhal yang lebih mendalam dan terperinci. Pada penelitian ini teknik interview juga digunakan sebagai dasar untuk menentukan perbaikan yang akan dilakukan dengan menginterview langsung user pengguna mesin produksi kain non-wovens tersebut.

\subsection{Teknik Pengolahan Data}

\section{Teknik Analisis OEE}

Dalam penelitian ini Overall Equipment Effectiveness digunakan sebagai teknik analisis untuk menentukan tingkat efektifitas mesin secara penuh. Untuk selanjutnya dilakukan analisis lebih lanjut menggunakan fishbone diagram. 


\section{Fishbone Diagram}

Setelah dilakukan analisa terhadap tingkat efektifitas mesin carding kain nonwovens dan dari hasil analisis akan didapat faktor utama penyebab rendahnya nilai OEE dari mesin produksi tersebut. Faktor yang menjadi prioritas tersebut akan dianalisis lebih lanjut menggunakan fishbone diagram dan hasil dari analisis tersebut akan digunakan sebagai dasar untuk menentukan perbaikan yang akan dilakukan.

3. 5 Why

Analisa 5 why ini digunakan untuk mencari root cause yang menjadi dasar pembentukan fishbone diagram. Analisa 5 why ini dengan mengulang pernyataan mengapa samapi pada akar permasalahan yang terjadi.

\section{HASIL DAN PEMBAHASAN}

\subsection{Pengumpulan Data}

1. Data Planned Downtime, Loading Time, Breakdown, Setup Ajustment dan Operating Time Mesin Produksi Kain Non-wovens.

Data pada tabel dibawah ini adalah data periode November 2018 sampai April 2019 sebelum dilakukannya perbaikan. Data ini digunakan untuk mencari nilai Availability dan Performance rate dari mesin produksi kain non-wovens.

Tabel 1. Data Downtime, Loading Time, Breakdown, Setup Ajustment, dan Operating Time November 2018 - April 2019

\begin{tabular}{|l|c|c|c|c|c|c|c|}
\hline Bulan & $\begin{array}{c}\text { Total } \\
\text { Menit }\end{array}$ & $\begin{array}{c}\text { Planned } \\
\text { Down } \\
\text { Time } \\
\text { (menit) }\end{array}$ & $\begin{array}{c}\text { Loading } \\
\text { Time } \\
\text { (menit) }\end{array}$ & $\begin{array}{c}\text { Break } \\
\text { Down } \\
\text { (menit) }\end{array}$ & $\begin{array}{c}\text { Setup } \\
\text { Ajustmen } \\
\text { (menit) }\end{array}$ & $\begin{array}{c}\text { Operating } \\
\text { Time } \\
\text { (menit) }\end{array}$ & $\begin{array}{c}\text { Actual } \\
\text { Operating } \\
\text { Time } \\
\text { (menit) }\end{array}$ \\
\hline Nov-18 & 32940 & 450 & 32490 & 2060 & 735 & 29695 & 28105,69 \\
\hline Des-18 & 30240 & 900 & 29340 & 3320 & 615 & 25405 & 23913,14 \\
\hline Jan-19 & 32040 & 720 & 31320 & 1530 & 450 & 29340 & 27879,93 \\
\hline Feb-19 & 31500 & 890 & 30610 & 2650 & 630 & 27330 & 25853,58 \\
\hline Mar-19 & 39240 & 1690 & 37550 & 2145 & 1160 & 34245 & 33179,09 \\
\hline Apr-19 & 39780 & 720 & 39060 & 2995 & 660 & 35405 & 33310,7 \\
\hline
\end{tabular}

Sumber : PT. Sumber Wovens Utama

\section{Jumlah Produksi dan Informasi Produk}

Komponen data yang digunakan untuk menghitung performance rate dari mesin produksi kain non-wovens adalah jumlah produksi dan ideal cycle time dari tiap jenis produk yang dihasilkan oleh mesin produksi tersebut.

Tabel 2. Jumlah Produksi November 2018 - April 2019

\begin{tabular}{|c|c|}
\hline Bulan & Jumlah Produksi $($ roll $)$ \\
\hline Nov-18 & 10103 \\
\hline Des-18 & 8152 \\
\hline Jan-19 & 11491 \\
\hline Feb-19 & 9915 \\
\hline Mar-19 & 12553 \\
\hline Apr-19 & 12910 \\
\hline
\end{tabular}

Sumber : Data jumlah produksi

Tabel 3. Informasi Produk

\begin{tabular}{|l|c|c|c|c|c|c|}
\hline \multicolumn{1}{|c|}{ Jenis Produk } & $\begin{array}{c}\text { Panjang } \\
\text { (meter) }\end{array}$ & $\begin{array}{c}\text { Ideal } \\
\text { Speed } \\
(\mathrm{m} / \mathrm{mnt})\end{array}$ & $\begin{array}{c}\text { Jumlah } \\
\text { Roll }\end{array}$ & $\begin{array}{c}\text { Jumbo } \\
\text { Cycle } \\
\text { Time } \\
\text { (menit) }\end{array}$ & $\begin{array}{c}\text { Pcs } \\
\text { Cycle } \\
\text { Time } \\
\text { (menit) }\end{array}$ & $\begin{array}{c}\text { Berat Perroll } \\
(\mathrm{kg})\end{array}$ \\
\hline NWO AT20 5000M & 5000 & 71 & 14 & 70,4 & 5,0 & 16,4 \\
\hline NWO AT20 3500M 15 & 3500 & 71 & 15 & 49,3 & 3,3 & 10,7 \\
\hline NWO AT20 3500M & 3500 & 71 & 12 & 49,3 & 4,1 & 13,4 \\
\hline
\end{tabular}




\begin{tabular}{|l|l|l|l|l|l|l|} 
IM (W6.20) 2000 M & 2000 & 65 & 30 & 30,8 & 1,0 & 3,8 \\
\hline IM (W6.20) 3000 M & 2000 & 65 & 30 & 46,1 & 1,5 & 5,7 \\
\hline IL 251 M & 1800 & 60 & 18 & 30,0 & 1,7 & 5,7 \\
\hline ADL 30 GSM & 3000 & 65 & 30 & 46,1 & 1,5 & 6,9 \\
\hline
\end{tabular}

Sumber : PT. Sumber Wovens Utama

\section{Data Cacat Produk Kain Non-wovens}

Data cacat produk terdiri atas produk cacat yang sudah menjadi per roll dan produk cacat yang berupa bs kain, untuk bs kain per roll didapat dari bs kain per kg dibagi dengan berat jenis produk per roll. Dibawah ini adalah tabel data cacat produk kain Non-Wovens periode November 2018 sampai April 2019. Data cacat produk ini akan digunakan sebagai data untuk mencari quality rate dari mesin produksi kain NonWovens

Tabel 4. Cacat Produk Kain

Non-wovens November 2018 - April 2019

\begin{tabular}{|c|c|c|c|}
\hline Bulan & Cacat Produk (roll) & Bs Produk $($ roll $)$ & Total $($ roll $)$ \\
\hline Nov-18 & 156 & 243 & 399 \\
\hline Des-18 & 32 & 103 & 135 \\
\hline Jan-19 & 56 & 215 & 271 \\
\hline Feb-19 & 228 & 104 & 332 \\
\hline Mar-19 & 138 & 177 & 315 \\
\hline Apr-19 & 88 & 172 & 260 \\
\hline
\end{tabular}

Sumber : PT. Sumber Wovens Utama

\subsection{Pengolahan Data}

\section{Perhitungan Nilai Overall Equipment Effectiveness Sebelum Perbaikan}

a. Availability

Perhitungan nilai availability mesin produksi kain non-wovens dilakukan perhari. Dimana nilai availability tersebut didapat dari pembagian antara operating time dengan loading time. Untuk data operating time dan loading time telah disajikan dalam tabel 4.1 diatas, dan untuk perhitungan nilai availability mesin produksi kain non-wovens bulan November sampai dengan April 2019 adalah sebagai berikut. Untuk rusmus perhitungan Availability menggunakan persamaan 2.4 diatas.

Availability rate November 2018 :

$$
\text { Availability }=\frac{29695}{32490} \times 100=91,4 \%
$$

Untuk nilai availability rate Desember 2018 - April 2019 tersaji pada tabel 4.5 dibawah.

\section{b. Performace Rate}

Faktor untuk menentukan besarnya nilai OEE yang kedua adalah nilai performance rate. Dimana nilai performance rate ini didapat dari perkalian antara jumlah produksi, dengan ideal cycle time atau actual operating time dibagi dengan operating time. Untuk nilai ideal cycle time dapat dilihat pada tabel 4.14 tentang informasi produk, sedangkan untuk jumlah produksi dapat dilihat pada tabel 4.2 diatas. Perhitungan performance rate mesin produksi kain non-wovens periode bulan November 2018-April 2019 adalah sebagai berikut. Untuk persamaan rumus performance rate menggunakan persamaan 2.5 diatas

Performance rate November 2018 :

$$
\text { Performance Rate }=\frac{28105,69}{29695} \times 100=94,5 \%
$$

Untuk nilai performance rate Bulan Desember 2018 - April 2019 tersahu pada tabel 4.5 dibawah.

c. Quality Rate 
Faktor untuk menentukan besarnya nilai OEE yang terakhir adalah quality rate. Dimana nilai quality rate ini didapat dari hasil pengurangan jumlah produksi dengan jumlah defect dibagi dengan jumlah produksi. Quality rate ini juga disebut sebagai yield produksi. Untuk nilai jumlah cacat produk dapat dilihat pada tabel 4.4 dan Rumus quality rate menggunakan persamaa 2.6 diatas.

Quality rate November 2018 :

$$
\text { Quality rate }=\frac{10103-399}{10103} \times 100=95,5 \%
$$

Untuk nilai quality rate bulan Sesember 2018 - April 2019 tersaji pada tabel 4.5 dibawah.

d. Overall Equipment Effectivenes

Nilai overall equipment effectivenes mesin produksi kain non-woven per hari adalah hasil kali antara 3 faktor diatas. Rumus untuk mencari OEE menggunakan persamaa 2.7.

Overall Equipment Effectivenens November2019

$$
\mathrm{OEE}=91,4 \% \text { x } 94,5 \% \text { x } 95,5 \%=82,5 \%
$$

Tabel 5. Nilai Overall Equipment Effectivenes November 2018 - April 2019

\begin{tabular}{|l|c|c|c|c|}
\hline \multicolumn{1}{|c|}{ Bulan } & $\begin{array}{c}\text { Availability } \\
(\mathbf{\%})\end{array}$ & $\begin{array}{c}\text { Performance } \\
\text { Rate (\%) }\end{array}$ & $\begin{array}{c}\text { Quality Rate } \\
(\mathbf{\%})\end{array}$ & OEE \\
\hline Nov-18 & 91,4 & 94,5 & 95,5 & 82,5 \\
\hline Des-18 & 86,8 & 94,2 & 97,9 & 80,6 \\
\hline Jan-19 & 93,8 & 94,9 & 97,2 & 86,6 \\
\hline Feb-19 & 89,5 & 94,9 & 95,9 & 81,4 \\
\hline Mar-19 & 90,6 & 96,2 & 96,8 & 87,4 \\
\hline Apr-19 & 90,8 & 94,3 & 97,5 & 83,4 \\
\hline Average & $\mathbf{9 0 , 4 8}$ & $\mathbf{9 4 , 8 2}$ & $\mathbf{9 6 , 8 1}$ & $\mathbf{8 3 , 2}$ \\
\hline
\end{tabular}

Sumber : Data yang diolah

\subsection{Analisa dan Pembahasan}

\section{Analisa}

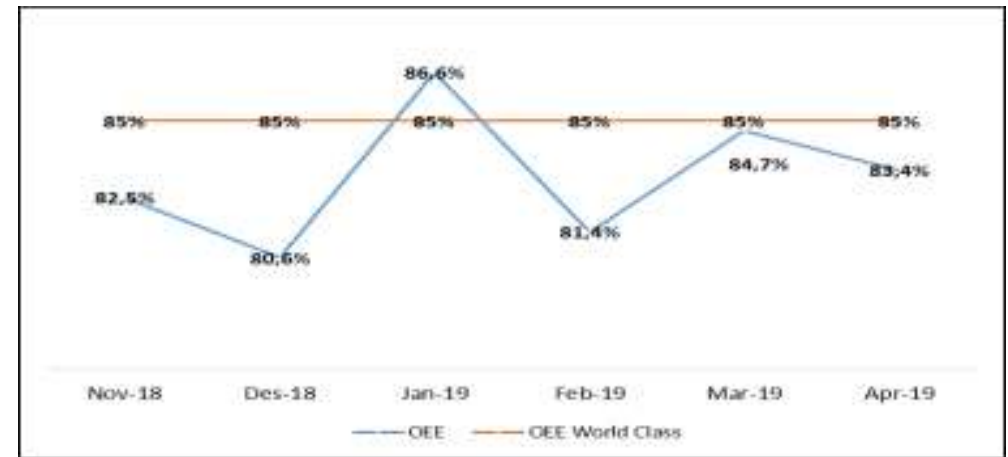

Gambar 4. Diagram Overall Equipment Effectiveness

Dari tabel 4.5 diatas dapat dilihat bahwa nilai Overall Equipment Effectivenes mesin produksi kain non-wovens masih dibawah nilai batas world class hanya pada bulan Januari 2019 nilai Overall Equipment Effectivenes berada diatas standar world class. Ini berarti secara keseluruhan mesin produksi kain non-wovens selama 6 bulan terhitung dari bulan November 2018 sampai April 2019 masih dikatakan belum produktif. Untuk melakukan perbaikan terhadap nilai Overall Equipment Effectiveness, perbaikan akan dilakukan berdasarkan faktor availability, performance rate, dan quality rate. Proses perbaikan nilai Overall Equipment Effectiveness dilakukan dengan menganalisa main cause dan root cause nilai Overall Equipment Effectiveness mesin produksi tidak sesuai harapan menggunakan analisa fishbone diagram. 
a. Availability

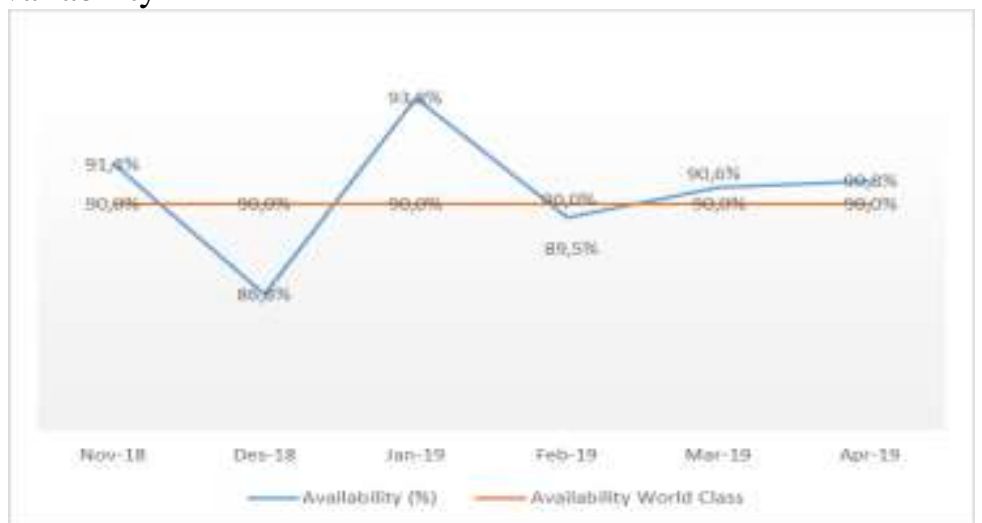

Gambar 5. Diagram Availability November 2018 - April 2019

Analisa lanjutan dilakukan menggunakan fishbone diagram untuk menganalisa faktor-faktor penyebab nilai availability mesin produksi kain non-wovens tidak tercapai pada bulan Desember dan Februari. Untuk analisa fishbone diagramnya adalah sebagai berikut.

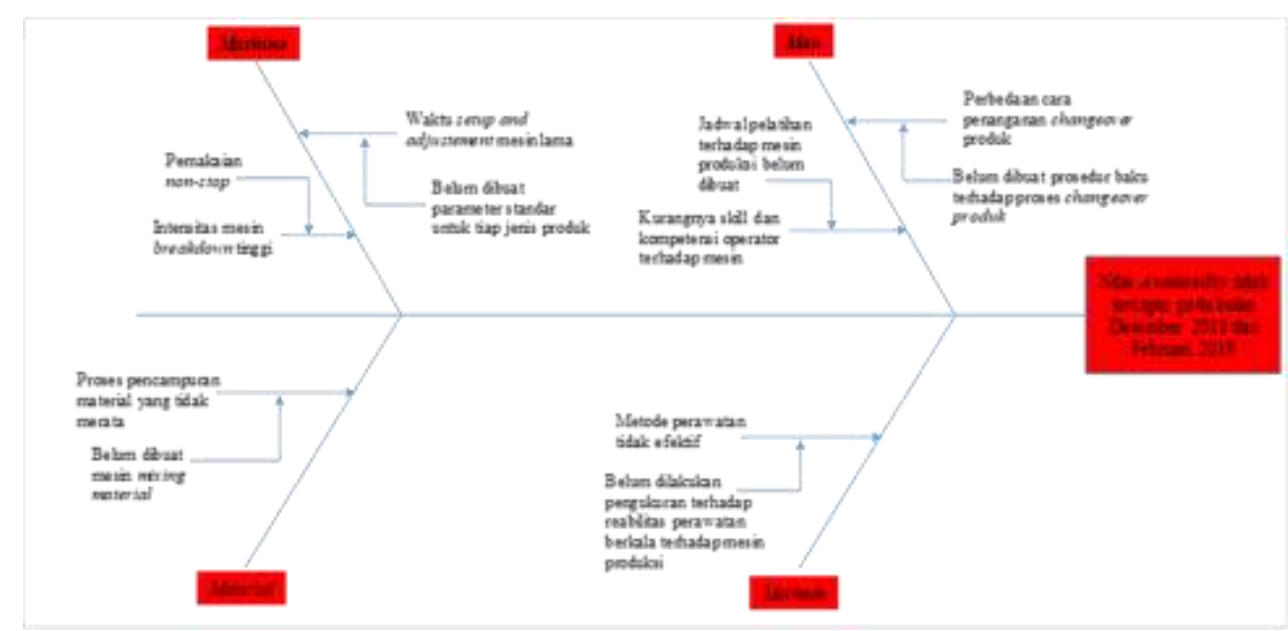

Gambar 6. Fishbone diagram Availability

b. Performance Rate

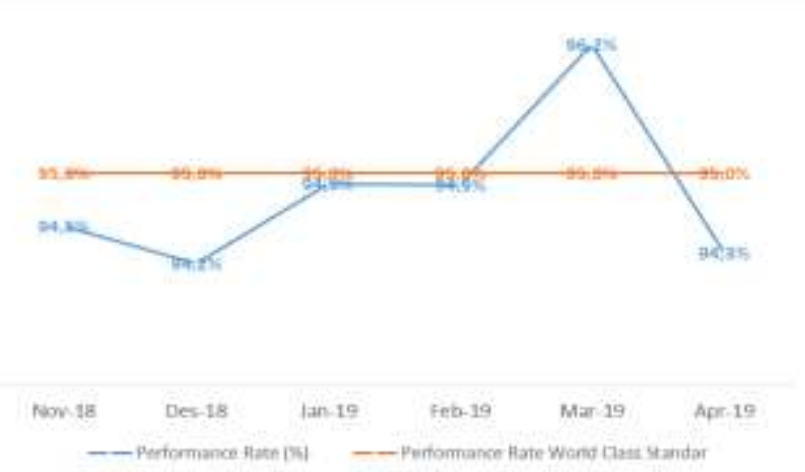

Gambar 7. Diagram Performance Rate November 2018 - April 2019

Penyebab rendahnya nilai performance rate pada gambar 4.4 diatasakan dianalisa menggunakan analisa kualitatif menggunakan fishbone diagram. Untuk analisa penyebab nilai performance rate tidak sesuai harapan adalah sebagai berikut. 


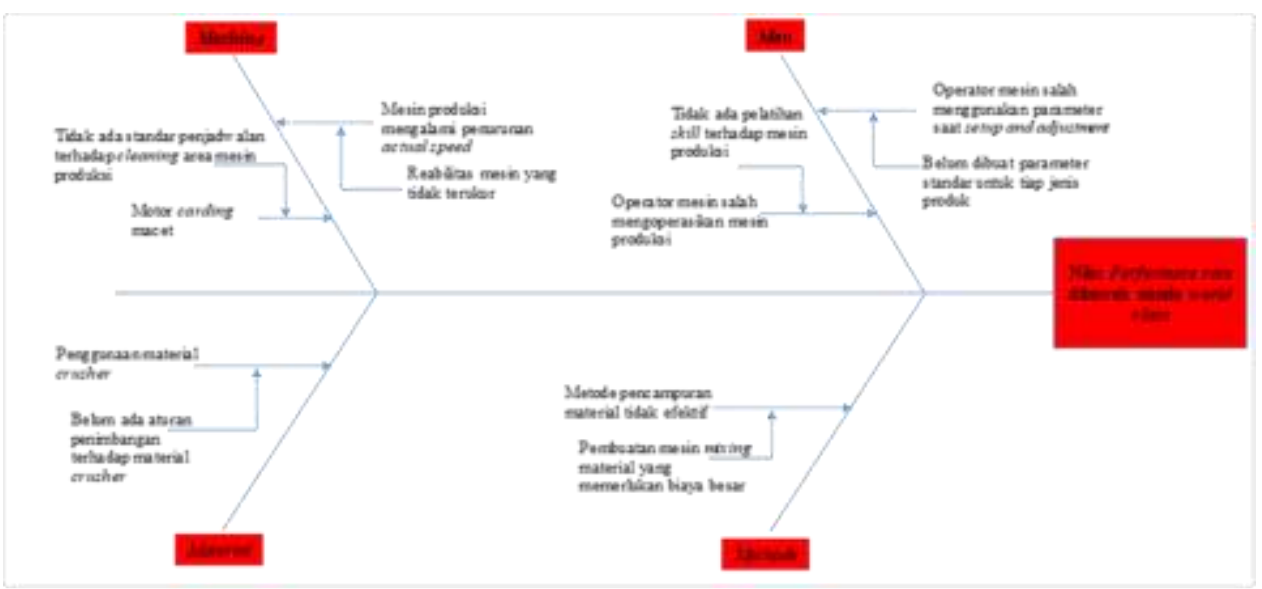

Gambar 8. Fishbone Diagram Performance Rate

c. Quality Rate

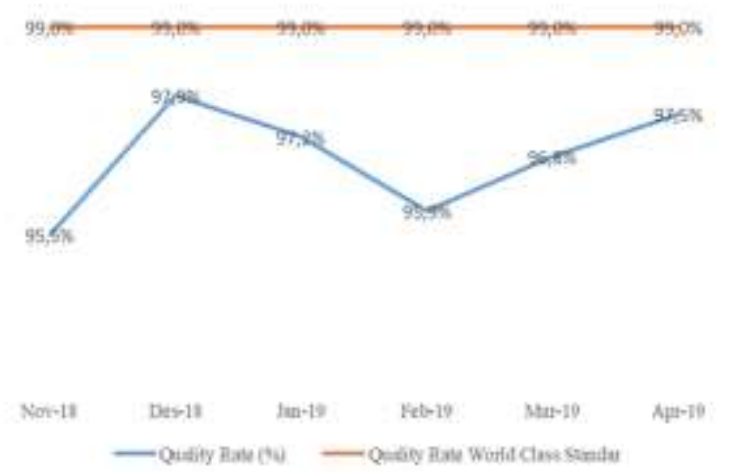

Gambar 9. Diagram Quality Rate November 2018 - April 2019

Analisa lajutan dari gambar 4.6 diatas untuk mengetahui penyebab nilai quality rate selalu berada dibawah standar world class menggunakan analisa fishbone diagram dibawah ini.

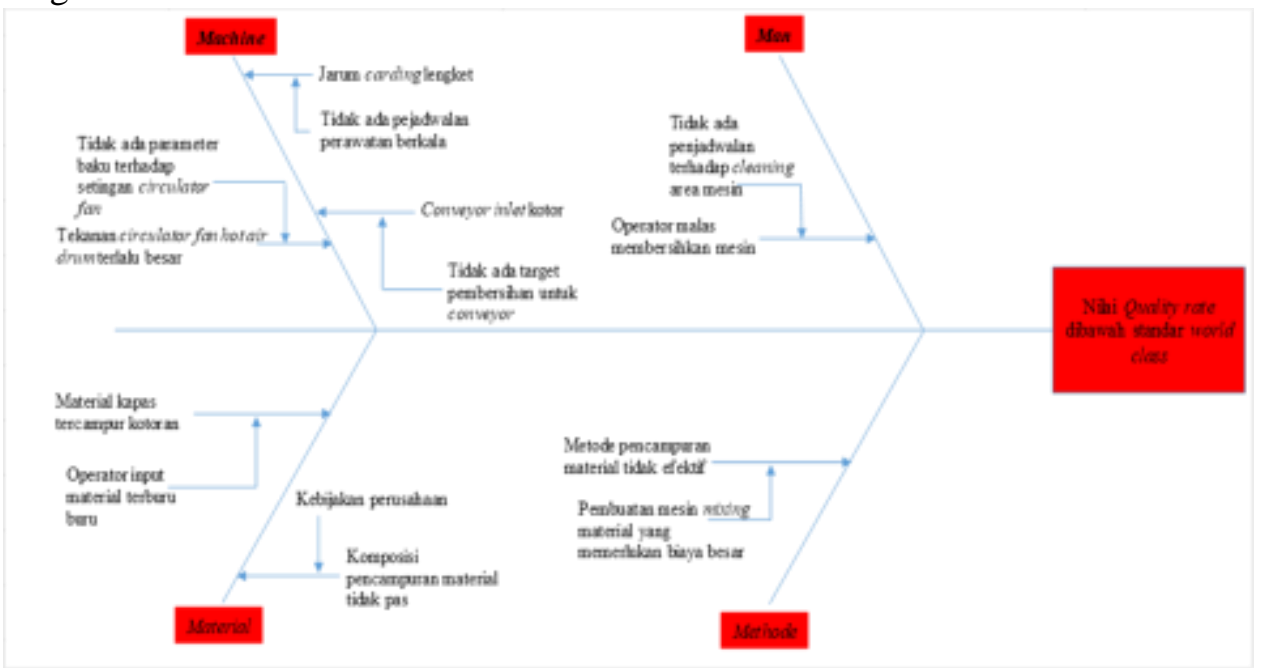

Gambar 10. Fishbone Diagram Quality Rate

Penerapan improvement untuk memperbaiki nilai Overall Equipment Effectiveness mesin produksi kain non-wovens adalah sebagai berikut.

a. Melakukan pengukuran terhadap reabilitas mesin produksi sebagai dasar untuk menentukan penjadwalan Perawatan berkala 
Pengukuran terhadap reabilitas mesin produksi diukur dengan mencari nilai mean time between failure (MTBF) atau nilai rata-rata waktu suatu mesin dapat di operasikan sebelum terjadinya kerusakan dan nilai mean time to repair (MTTR). Dari data operating time mesin produksi kain non-wovens diatas dapat diketahui bahwa jumlah waktu total operation mesin produksi kain non-wovens sebesar 200.370 menit, waktu breakdown time produksi 8.170 menit selama bulan november 2018 - April 2019 dengan frequinsi breakdown sebanyak 56 kali breakdown. Maka nilai MTBF dan MTTR mesin produksi kain non-wovens adalah sebagai berikut. Rumus MTBF dan MTTR menggunakan persamaan 2.8 dan 2.9 $\mathrm{MTBF}=\frac{\text { Total Operation TIme }}{\text { Frequensi Breakdown }}$

$$
\begin{array}{r}
\text { MTBF }=\frac{200.370}{56}=3578,03 \text { menit atau } 60 \text { jam } \\
\text { MTTR }=\frac{\text { Breakdown Time }}{\text { Frequensi Breakdown }} \\
\text { MTTR }=\frac{8.170}{56}=145,9 \text { menit atau 2,5 jam }
\end{array}
$$

Jadi waktu rata-rata antar breakdown dengan breakdown berikutnya adalah 60 jam dengan waktu breakdown selama 2,5 jam. Perhitungan MTBF dan MTTR ini akan dijadikan sebagai penjadwalan perawatan mesin produksi.

b. Aturan penimbangan terhadap material crusher

Untuk regulalsi penentuan berapa berat material crusher yang di input ke bale opener dihitung dari kebijakan penggunaan material crusher dari pabrik atau sebesar $50 \mathrm{~kg}$ dibagi dengan frekuensi input material kedalam bale opener. Sedangkan untuk frekuensi input materia didapat dari rata rata pemakaian kapas perhari dibagi dengan kapasitas maksimal bale opener yaitu $40 \mathrm{~kg}$.

$$
\begin{aligned}
& \text { Frekuensi input material }=\frac{3200}{30}=106,7 \text { atau } 107 \mathrm{kali} \\
& \text { Berat material crusher sekali input }=\frac{50}{107}=0,47 \text { atau } 0,5 \mathrm{~kg}
\end{aligned}
$$

Jadi untuk sekali penimbangan komposisi material crusher $0,5 \mathrm{~kg}$ dan komposisi material utama $40 \mathrm{~kg}$.

c. Pembuatan parameter standar tiap produk

Karena parameter bersifat tentatif, artinya parameter dapat berubah sewaktu waktu tergantung dengan depresiasi mesin produksi. Maka penentuan parameter standar tiap produk dilihat dari data parameter terbaik menurut tingkat OEE pada bulan sebelumnya. Nilai OEE diambil sebagai acuan karena dalam analisa akar masalah, parameter mesin berada pada ketiga faktor dalam OEE tersebut.

Tabel 6. Nilai OEE Terbaik tiap Produk

\begin{tabular}{|l|l|c|}
\hline \multicolumn{1}{|c|}{ Jenis Produk } & \multicolumn{1}{c|}{ Tanggal } & Nilai OEE \\
\hline NWO AT20 3500 & 24-Mar-19 & $97,9 \%$ \\
\hline NWO AT20 5000 & 25-Des-19 & $97,8 \%$ \\
\hline NWO AT20 3500M 15 & 01-Apr-19 & $98,8 \%$ \\
\hline IM (W6.20) 2000M & 11-Jan-19 & $93,6 \%$ \\
\hline IM (W6.20) 3000M & 22-Des-18 & $93,8 \%$ \\
\hline IL 251 M & 07-Feb-19 & $99,3 \%$ \\
\hline ADL 30 & 27-Feb-19 & $89,7 \%$ \\
\hline
\end{tabular}

Parameter dari tiap produk berdasarkan analisa nilai OEE terbaik diatas.

d. Membuat Standar Prosedur changeover produk

Standar prosedur changeover dibuat dengan menggunakan pendekatan single minutes exchange of die (SMED) pendekatan ini dilakukan untuk mereduksi waktu changeover produk Agar dapat berimplikasi terhadap kenaikan availability mesin produksi. Pada tabel 4.7 dan 4.8 dibawah ini akan disajikan aktifitas-aktifitas yang dilakukan pada saat changeover produk sebelum dilakukan perbaikan serta aktifitas changover produk setelah penerapan SMED. 
Tabel 7. Aktifitas Changeover Produk Sebelum Improvement

\begin{tabular}{|c|c|c|}
\hline Aktifitas & $\begin{array}{l}\text { Waktu } \\
\text { (menit) }\end{array}$ & Event \\
\hline Kalibrasi parameter mesin & 10 & Internal \\
\hline Persiapan material baru & 20 & Internal \\
\hline Running & 5 & External \\
\hline kuras material lama & 10 & External \\
\hline Stop, Check Tensile streght produk & 20 & Internal \\
\hline Running & 5 & External \\
\hline
\end{tabular}

Sumber : Analisa lapangan PT.Sumber Wovens Utama

Table 8. Aktifitas Changeover Produk Setelah Penerapan SMED

\begin{tabular}{|c|c|c|}
\hline Aktifitas & $\begin{array}{l}\text { Waktu } \\
\text { (menit) }\end{array}$ & Event \\
\hline Kuras material + kalibrasi & 10 & External \\
\hline Stop, Check Tensile streght produk & 10 & Internal \\
\hline Running & 5 & External \\
\hline Total & 25 & \\
\hline
\end{tabular}

Sumber : Analisa lapangan PT. Sumber Wovens Utama

Dari Tabeli 4.7 dan Tabel 4.8 diatas dapat dilihat terjadi penurunan waktu changeover produk dari yang sebelum dilakukan improvement waktu changeover produk selama 70 menit setelah dilakukan perbaikan menggunakan SMED waktu changeover produk berkurang menjadi 25 menit.

e. Membuat penjadwalan terhadap cleaning area mesin produksi

Aktifitas cleaning area mesin produksi dilakukan 4 kali dalam satu sift, atau setiap 2 jam sekali.

Tabel 4.9 Before and After Perbaikan

\begin{tabular}{|c|c|c|}
\hline No & Before & After \\
\hline 1 & $\begin{array}{l}\text { Tidak ada jadwal pelatihan } \\
\text { terhadap mesin produksi }\end{array}$ & $\begin{array}{l}\text { Melakukan pelatihan informal saat } \\
\text { breafing sift mengenai mesin } \\
\text { produksi, dan kendala kendala yang } \\
\text { dialami }\end{array}$ \\
\hline 2 & $\begin{array}{l}\text { Tidak ada standar prosedur } \\
\text { changeover produk }\end{array}$ & $\begin{array}{l}\text { Terdapat prosedur changeover } \\
\text { produk }\end{array}$ \\
\hline 3 & $\begin{array}{l}\text { Tidak ada penjadwalan perawatan } \\
\text { berkala }\end{array}$ & $\begin{array}{l}\text { Melakukan penjadwalan perawatan } \\
\text { bekala selama } 2,5 \text { jam setiap } 60 \text { jam } \\
\text { sekali }\end{array}$ \\
\hline 4 & $\begin{array}{l}\text { Tidak ada parameter standar } \\
\text { produk }\end{array}$ & Terdapat parameter standar produk \\
\hline 5 & Tidak ada mesin mixing material & $\begin{array}{l}\text { Menyediakan wadah besar sebagai } \\
\text { tempat pengganti mesin mixing } \\
\text { material }\end{array}$ \\
\hline 6 & $\begin{array}{l}\text { Tidak ada standar penjadwalan } \\
\text { cleaning area mesin }\end{array}$ & $\begin{array}{l}\text { cleaning area mesin dilakukan } \\
\text { setiap } 2 \text { jam sekali dengan } \\
\text { membawa check sheet cleaning area } \\
\text { mesin }\end{array}$ \\
\hline 7 & $\begin{array}{l}\text { Tidak ada penyuluhan terhadap } \\
\text { operator input material }\end{array}$ & $\begin{array}{l}\text { Melakukan penyuluhan terhadap } \\
\text { operator input material setiap } \\
\text { breafing shift }\end{array}$ \\
\hline 8 & $\begin{array}{l}\text { Tidak ada regulasi penimbangan } \\
\text { kapas crusher }\end{array}$ & $\begin{array}{l}\text { Terdapat regulasi penimbangan } \\
\text { kapas crusher }\end{array}$ \\
\hline
\end{tabular}

Sumber : Hasil perbaikan 


\section{Pembahasan}

\section{a. Perhitungan Nilai Overall Equipment Effectiveness Mesin Produksi Kain Non-wovens setelah Perbaikan}

Tabel 4.10 Overall Equipment Effectivenes Mesin Produksi Kain Non-wovens Setelah Perbaikan

\begin{tabular}{|c|c|c|c|c|}
\hline Periode & Availability (\%) & $\begin{array}{c}\text { Performance } \\
\text { Rate (\%) }\end{array}$ & $\begin{array}{c}\text { Quality } \\
\text { Rate (\%) }\end{array}$ & OEE \\
\hline 15 - 28 Mei 2019 & $94,7 \%$ & $94,8 \%$ & $97,9 \%$ & $87,9 \%$ \\
\hline 10 - 30 Juni 2019 & $95,2 \%$ & $95,3 \%$ & $98,0 \%$ & $89,0 \%$ \\
\hline Average & $\mathbf{9 5 , 0 \%}$ & $\mathbf{9 5 , 1 \%}$ & $\mathbf{9 8 , 0 \%}$ & $\mathbf{8 8 , 5 \%}$ \\
\hline
\end{tabular}

Sumber : Data yang diolah

Dari tabel 4.10 diatas dapat dilihat bahwa nilai Overall Equipment Effectiveness dari mesin produksi kain no-wovens setelah dilakukan perbaikan mengalami peningkatan dari yang sebelum dilakukan perbaikan memiliki nilai Overall Equipment Effectiveness sebesar 83,2\% menjadi 88,5\%. Kenaikan nilai Overall Equipment Effectiveness ini ditandai dengan penurunan breakdown time dari $7,34 \%$ menjadi $3,94 \%$, penurunan waktu setup adjustement dari $2,12 \%$ menjadi $1,10 \%$, penurunan lose time dari $5,06 \%$ menjadi $4,87 \%$, penurunan defect produk dari 2,63\% menjadi 1,96\%. Penurunan breakdown time, setup adjustement, lose time, dan jumlah cacat produk akan sangat berpengaruh terhadap peningkatan produktifitas yang dihasilkan. Dengan menggunakan waktu sebelum perbaikan dan nilai Overall Equipment Effectivenes sebesar 83,2\% (sebelum perbaikan) perusahaan akan menghasilkan produk sebanyak 65124 pcs produk dari semua jenis selama 6 bulan, sedangkan jika perusahaan menggunakan waktu yang sama sebelum perbaikan tetapi nilai Overall Equipment Effectiveness sebesar 88,5\% maka kita akan menghasilkan produk sebanyak 66971 atau meningkan sebanyak 1847 pcs produk selama 6 bulan.

\section{KESIMPULAN DAN SARAN}

\subsection{Kesimpulan}

Dari hasil penelitian terhadap evaluasi nilai Overall Equipment Effectiveness dan upaya perbaikan produktifitas mesin produksi kain non-wovens diatas maka dapat disimpulkan.

1. Nilai Overall Equipment Effectiveness mesin produksi kain non-wovens sebesar $82,5 \%$ pada bulan November 2018, 80,6\% pada bulan Desember 2018, 86,6 \% pada bulan Januari 2019, 81,4\% pada bulan Februari 2019, 84,7\% pada bulan Maret 2019, 83,4\% pada bulan Februari 2019, atau memiliki rata-rata rata sebesar 83,2\%. Nilai Overall Equipment Effectiveness mesin produksi tersebut masih dibawah standar world class sebesar 85\%. Hanya pada bulan Januari 2019 nilai Overall Equipment Effectiveness berada diatas nilai world class, tetapi untuk ratarata nilai Overall Equipment Effectiveness masih dibawah standar world class

2. Penyebab nilai overall equipment efectiveness tidak sesuai harapan adalah sebagai berikut :

- Kurangnya skill dan kompetensi operator terhadap mesin dan peralatan produksi

- Perbedaan cara penanganan changeover produk baru oleh tiap regu

- Intensitas breakdown tinggi

- Waktu setup and ajustement mesin yang lama

- Proses pencampuran material yang tidak merata

- Metode perawatan yang digunakan tidak efektif

- Operator mesin salah mengoprasikan mesin produksi

- Meisin produksi yang mengalami penurunan aktual kecepatan

- Motor carding macet yang mengakibatkan minor stoppages

- Penggunaan material crusher mengakibatkan penurunan actual speed

- Operator malas membersihkan mesin produksi 
- Conveyor inlet kotor

- Tekanan circulator fan hot air drum terlalu besar

- Jarum carding lengket

- Material yang tercampur kotoran

- Komposisi pencampuran material tidak pas

3. Perbaikan yang dilakukan untuk meningkatkan nilai Overall Equipment Effectiveness mesin produksi kain non-wovens adalah sebagai berikut :

- Menginformasikan kepada kepala bagian untuk dilakukan pelatihan formal terhadap mesin dan peralatan produksi bagi semua operator

- Membuat pelatihan informal saat breafing

- Membuat standar prosedur changeover produk untuk menyeragamkan proses changeover produk oleh tiap regu

- Membuat jadwal perawatan berkala terhadap mesin produksi

- Membuat parameter standar tiap jenis produksi dan memperbaruinya kurun waktu 1 bulan sekali

- Menyediakan wadah besar untuk proses pencampuran material secara manual sebelum material masuk kedalam bale oppener

- Melakukan pengukuran terhadap reabilitas mesin produksi

- Membuat penjadawalan cleaning area mesin produksi

- Membuat aturan penimbangan terhadap material crusher

- Memberikan penyuluhan terhadap operator input material untuk berhati hati saat proses input material.

4. Nilai Overall Equipment Effectiveness mesin produksi kain non-wovens setelah dilakukan perbaikan selama kurun waktu 2 bulan memiliki nilai rata rata sebesar $88,5 \%$ yang terdiri dari 87,9\% pada periode 15 - 28 Maret 2019 dan 89,0\% pada periode perbaikan 10 - 30 Juni 2019. Nilai Overall Equipment Effectiveness mesin produksi kain non-wovens mengalami peningkatan dari sebelum dilakukan perbaikan.

\subsection{Saran}

Penelitina terhadap nilai Overall Equipment Effectiveness mesin produksi kain nonwovens ini dapat dijadikan dasar perbaikan bagi perusahaan untuk meningkatkan produktivitas yang dihasilkan. Nilai Overall Equipment Effectiveness juga menjadi sebuah key performance indicator untuk melihat seberapa efektif mesin produksi bekerja jika dilihat dari availability, performance, dan kualitas yang dihasilkan. Penggunaan Overall Equipment Effectiveness juga tidak terbatas hanya kepada mesin dan peralatan produksi saja, Overall Equipment Effectiveness juga dapat di terapkan pada seluruh sumberdaya yang dimiliki oleh sebuah manufaktur, baik itu material, maupun man power. Untuk proses pengambilan data setelah perbaikan, disarankan bisa lebih lama jangka waktu yang digunakan agar hasil penelitian lebih meyakinkan.

\section{DAFTAR PUSTAKA}

Almeanazel, O.T.R. (2010). Total Productive Maintenance Revies and Overall Equipment Effectiveness Measurement. JJMIE, Vol.4 No.4, 517 - 522

Bilianto, B.Y. dan Ekawati, Y. (2016). Pengukuran Efektifitas Mesin Menggunakan Overall Equipment Effectiveness Untuk dasar Usulan Perbaikan. Jurnal Ilmiah Teknik Industri, 116 - 126

Diniati, D. dan Susanto, R. (2017). Analisis Total Productive Maintenance (TPM) Pada Stasiun Kernel Dengan Menggunakan Metode Overall Equipment Effectiveness (OEE) Di PT. Surya Agrolika Reksa. Jurnal Teknik Industri, Vol. 3 No.2, 60-64

Esa, F. dan Yusof, Y. (2016). Implementing Overall Equipment Effectiveness (OEE) and Sustainable Competitive Advantage : A Case Study Of Hicom Diecasting SDN, 
BHD, HDSB. Journal Of Engineering and Applied Sciences, Vol. 11 No. 1, 119 203

Gaspersz, V. (1998). Manajemen Produktivitas Total. Jakarta : PT. Gramedia Pustaka Utama

Hamza, A.A. (2015). Analisa Total Productive Maintenance dengan Menggunakan Metode Overall Equipment Effectiveness di PT. Karung Emas. Jurnal MATRIK, Vol. 16 No. $1,33-50$

Hassani, L. Hashemzadeh, G. (2015). The Impact of Overall Equipment Effectiveness o Production Losses In Moghan Cable \& Wire Manufacturing. International Journal for Quality Research, 565 - 576

Irwan. Haryono, D. (2015). Pengendalian Kualitas Statistik (Pendekatan Teoritis dan Aplikatif). Bandung : ALFABETA.

Iswandi, Sayuti, M. (2016). Analisis Prouktivitas Perawatan Mesin dengan Metode TPM (Total Productive Maintenance) Pada Mesin Mixing Section. Jurnal Of Mechanical Science and Tecnology, Vol.4 No.2, 10-13

Karismawan, F. dan Katias, P. (2015). Pengukuran Kinerja Mesin Perusahaan Menggunakan Overall Equipment Effectiveness dan Usulan Perbaikan Mengunakan Diagram Sebab Akibat (Fishbone) Pada CV. Jati Makmur Pasuruan. Jurnal Manajemen Teori dan Terapan. Vol. 8 No. 2, 107 - 114

Katkamwar, S.G. dan Wadatkar, S.K. (2013). Study Of Total Productive Maintenance \& Its Implementing Approach in Spinning Industries. IJETT, Vol. 4 No. 5, $1750-$ 1754

Kurniawan, F. (2013). Manajemen Perawatan Industri Teknik dan Aplikasi. Yogyakarta : Graha Ilmu.

Krisnaningsih, E. (2015). Usulan Penerapan TPM dalam Rangka Peningkatan Efektifitas Mein Dengan OEE Sebagai Alat Ukur di PT. XYZ. Jurnal PROSISKO, Vol.2 No.2, 13-26

Mukhril. (2014). Penerapan Pada Industri Total Productive Maintenance \& Total Quality Management. Tangerang : MEGAKARYA.

Nursubiyantoro, E. Puryani. dan Rozaq, M.I. (2016). Implementasi Total Productive Maintenance (TPM) dalam Penerapan Overall Equipment Effectiveness (OEE). Jurnal OPSI, Vol. 9 No. 1, $24-32$

Nurfaizah, Ulfi. Adianto, R.H. dan Prasetyo, H. (2014). Rancangan Penerapan Total Productice Maintenance (TPM) di Bagian Press II PT. XYZ. Jurnal Online Institut Teknologi Nasional, Vol. 1 No.1, 340 - 353

Puvanasvaran, Perumal. (2013). Consideration Of Demand Rate in Overall Equipment Effectivenes (OEE) on Equipment with Constant Process Time. JIEM, 507 - 524

Winarno, H. dan Negara, Y.N. (2014). Analisis Productive Maintenance di PT. Sankyu Indonesia International. Jurnal Intech Teknik Industri, 24-32

Yulius, H. Mardian, I. (2018). Evaluasi Tingkat Efektivitas Mesin Raw Mill Dengan Menggunakan Metode Overall Equipment Effectiveness. Jurnal Teknologi, Vol. 8 No. $1,45-54$ 